\title{
POSSIBLE CALCULATOR ADDICTION IN STUDENTS WHILE PERFORMING SIMPLE CALCULUS OPERATIONS IN SOLVING MATHEMATICS PROBLEMS
}

\author{
Sead Rešić1 \\ Maid Omerović \\ Tarik Baždalić \\ Amila Osmić
}

\section{Review paper}

DOI: $10.21554 /$ hrr.091710

Department of Mathematics, Faculty of Sciences, University of Tuzla, Bosnia and Herzegovina

Faculty of Education Travnik, Bosnia and Herzegovina

Mixed secondary construction school Tuzla, Bosnia and Herzegovina

Received: 14.06 .2017

Accepted: 21.08.2017

\begin{abstract}
Contemporary learning processes in schools and universities could not be imagined without the use of computers and calculators. Naturally, all is good if they are used in order to acquire new knowledge or solve problems from expert subjects in technical schools, which demand large quantity of simple mathematical operations. However, what if frequent use of calculators, either pocket or those installed on every home and school computer, becomes an addiction in students who begin using them while calculating simple mathematical operations, such as multiplying or adding and detracting one-digit numbers or numbers smaller than 20, when they should know this by heart? We arrived at this hypothesis during knowledge tests for students after regular demonstrations and elaborations of Mathematics subject matter. In order to confirm or deny this hypothesis, generic/developmental method, that is, survey was used as one of research techniques (Selimović, 2013., p. 104). The survey was conducted in March during academic 2016/2017 and the sample consisted of 59 students in 2nd grade of Grammar School Tešanj.
\end{abstract}

Key words: simple calculus operations, one-digit numbers, multiplication table, adding, detracting, calculator.

\section{INTRODUCTION}

Contemporary life could not be imagined without the use of computers in various human activities and work areas. Mass production and use of different kinds of calculators and other electronic aids has greatly simplified work in accounting, commerce, engineering and other human activities where a lot of simple mathematical operations need to be done in a short time. Before the birth of electronic calculators it was a long and tedious work of a great number of employed clerks who spent their entire work life doing simple mathematical operations either by hand or using mechanical calculus aids.
Mass production and use of calculators has greatly facilitated teachers and students in contemporary classes in subjects where solving problems demands completing a certain number of basic mathematical operations with multi-digit numbers and where basic mathematical operations are only means to apply newly acquired knowledge. Such is the case with Physics classes, where solving practical problems demand incorporating given values of parameters and physical dimensions into empirical or derived formulas in order to gain values of other physical dimensions.

\footnotetext{
Correspodence to:

Sead Rešić, Department of Mathematics, Faculty of Sciences, University of Tuzla

Šabana Zahirovića 10, Tuzla, B\&H

Phone: +38761 101230

E-mail: sresic@hotmail.com
} 
However, contemporary Mathematics classes demand successful and rational work. The center is placed on the process of acquiring knowledge, where solving problems requires very few basic mathematical operations, mostly with one-digit numbers which should be easily completed by heart without the use of computing aids

The subject of this research is to examine possible students' addiction to calculators while performing the most basic calculus operations while solving mathematical problems. In other words, the subject of this research is to determine whether students will mechanically use calculators in learning new Mathematics subject matter and solving problems even when they need to add or multiply two one-digit positive or negative numbers, or use their own biological memory and 'remember' that they learned it in beginning grades of elementary school.

\section{GOAL AND TASKS OF RESEARCH}

Basic goal of this research is to determine whether and to what extent students use calculators while solving mathematical problems even when the problem requires one or two basic calculus operations with onedigit numbers, which they would need to do by heart with no calculus aids. So, what needs to be determined is to what extent is everyday use of calculus aids present in students while learning Mathematics subject matter.

The subject of research and formulated goal of research yields the tasks of research.

1.To determine whether and to what extent students use calculus aid - calculator in performing basic calculus operations.

2.To determine whether overuse of calculators (if it exists) has gone to an extent that students are using it for the most basic calculus operations between two one-digit numbers.

3.To indirectly determine whether Mathematics knowledge that students acquired in lower grades of elementary school - basic calculus operations - is successfully used when needed in secondary school or whether the overuse of calculators got is 'stuck somewhere in neurons of brain cortex'.
The above-mentioned goal and tasks of research set the zero hypothesis as follows:

H0: Gained knowledge in Mathematics from lower grades of elementary schools is successfully used among students when they need it while solving mathematical problems in secondary school, so they do not need calculators for this. Students use calculators in Mathematics classes in secondary school only when they solve problems which demand a great number of simple calculus operations with multiple-digit numbers in sort time, or when they need to perform calculus operations which cannot be done by heart (rooting, logarithm, trigonometry operations).

Opposite to zero hypothesis we fing the main hypothesis of the research, which states:

$\mathrm{H}$ : Students overuse calculators so much that even for the simplest occasional calculus operations in Mathematics classes in secondary school they use calculators, so it can be said that they have become addicted to calculators.

The main hypothesis can be broken into two sub hypotheses:

H1: From the lowest grades of elementary school, students use calculus aids for solving Mathematics problems, so they never completely absorbed knowledge about basic calculus operations, which lead to their addiction to calculators in their later education.

H2: Students started using calculators in secondary school in Mathematics and Physics classes when they needed to perform calculus operations which they could not complete by heart, so this need later grew into completing simple calculus operations with a calculator, which then lead to students' addiction to calculators.

\section{RESEARCH}

In order to ensure quality survey conditions and acquire reliable empirical data, the characteristics and size of sample were taken into account. The sample comprised of students in three 2nd grade classes in Grammar School Tešanj, in total 59 students - examinees. When it comes to size of the sample, this is medium sized sample, but the survey does not emphasize on the number of examinees but rather on results of the research. 
In order for survey to be adequate, good and successful, the questionnaire needed to comply with the following terms:

- 'To contribute to examinees' high motivation;

- To ask examinees necessary information which cannot be gained any other way;

- To be optimally long and not require a lot of time to fill;

- To meet aesthetic standards (look attractive and well put together);

- To avoid intimate questions;

- To guarantee anonymity;

-T o be clear;

- To have questions formulated clearly, specific, short, unambiguous, understandable, without extra unnecessary words and unknown and unusual terms;

-To have questions which are not suggestive'. (Pedagoška enciklopedija I, 1989, p. 27)

Regarding general information, every examinee needed to write gender, class and average Mathematics grade on the questionnaire.

The questionnaire was closed and comprised of eight questions, and every question offered three answers. The answers were graded 1 to 3, while examinees did not know the grading tables in order to avoid suggestive questions. Answers which were offered had 1 point for supporting zero hypothesis, 2 points to show that examinees are between zero and main hypothesis, and finally, 3 points for supporting the main hypothesis.

So, scoring for given answers to all eight questions in the questionnaire was done so that the sum of points cannot be less than 8 or more than 24 . From this range of possible sums of points for completed questionnaire a scale was made based on which every examinee was classified in one of three possible groups, as follows:

1.Examinees whose sum of points is $8-13$ fall into the group of those not addicted to calculator and who perform occasional simple calculus operations in Mathematics by heart.

2.Examinees whose sum of points is 14-16 fall into the group of those who do not find their way in Mathematics classes without the use of calculator, that is, they occasionally make mistakes in simple calculus operations and it can be said that they are borderline addicted to calculators.
3. Examinees whose sum of points is 17-24 fall into the group of those who perform every calculus operation in Mathematics classes using calculators, regardless of its kind and volume, that is they can be said to be addicted to calculators.

\section{RESULTS}

During analysis and interpretation of research results the percentage procedure was used as quick and simplest manner of statistical analysis.

Therefore, upon the completed survey with 59 examinees and examining as well as analyzing the questionnaire, the following results were gained:

1.Group with points ranging 8-13 comprised of $44 \mathrm{ex}-$ aminees, with the percentage $74.58 \%$.

2.Group with points ranging 14-16 comprised of 6 examinees, with the percentage $10.17 \%$.

3. Group with points ranging 17-24 comprised of 9 examinees, with the percentage $15.25 \%$.

\section{CONCLUSION}

Based on acquired results of the survey it can be stated that majority of representative sample (3/4) is not addicted to calculators and performs occasional calculus operations in Mathematic classes by herat without the use of calculators.

Only $1 / 10$ of the representative sample makes occasional mistakes in basic calculus operations if they do not have a calculator, so it can be said that they are borderline addicted to calculators.

Approximately $1 / 7$ of the representative sample performs every calculus operation regradless of it type and size with a calculator, so this manner of use of calculators is classified as addiction.

Based on the demonstrated results, it can be seen that zero hypothesis is confirmed, while the main hypothesis with its sub hypotheses is luckily denied. Those examinees who confirmed the main hypothesis are merely exceptions who confirm the rule.

\section{REFERENCES}

Pedagoška enciklopedija I i II (1989.) Sarajevo: Zavod za udžbenike i nastavna sredstva Svjetlost

Rešić, S. (2017). Metodika nastave matematike.Tuzla.

Selimović, H., Rodić, N. \& Selimović, N. (2013). Metodologija istraživanja, Univerzitet u Travniku, Edukacijski fakultet. 